\title{
Stasis and Flux: Czech Puppet Culture in Columbus, Ohio (Winter/Spring 2013)
}

For some theatre artists and audiences, the items remaining after all live activities associated with that event become inert - lifeless and, to varying degrees, worthless. For others, items and ephemera associated with past theatre productions retain value as individual works of art, exemplars of a historical moment, or both. Exhibitions of theatre items are almost always static, staged beautifully in halls to be admired by visitors with performative associations residing exclusively in the imaginations of viewers. A full understanding of the influence and impact of any theatrical technique is best attained by seeing that technique in action, in the fluid context of live performance. This was the guiding principle for two events designed to illuminate the world of Czech puppet culture in the United States over the course of several months.

On 4 August 2013, an exhibition entitled Strings Attached: The Living Tradition of Czech Puppets closed at the Columbus Museum of Art in the state of Ohio. The fivemonth exhibition was the product of four years of planning by the Museum and the Arts and Theatre Institute, Prague. In April 2013, a theatre production co-conceived and designed by Petr Matásek was staged at the Ohio State University, also in Columbus, Ohio. Several of Matásek's previous works were shown in the exhibit and a figure, also designed by him, appeared in the production.

In this way, historical artefacts and contemporary practices were joined in a multifaceted display of Czech culture for Ohio audiences.

Although Columbus, Ohio might not seem a likely destination for things Czech, Strings Attached was the fourth in a series of exhibitions beginning with Metaphor and Irony: Czech Scenic and Costume Design 1920-1999 (2000), and followed by Metaphor 


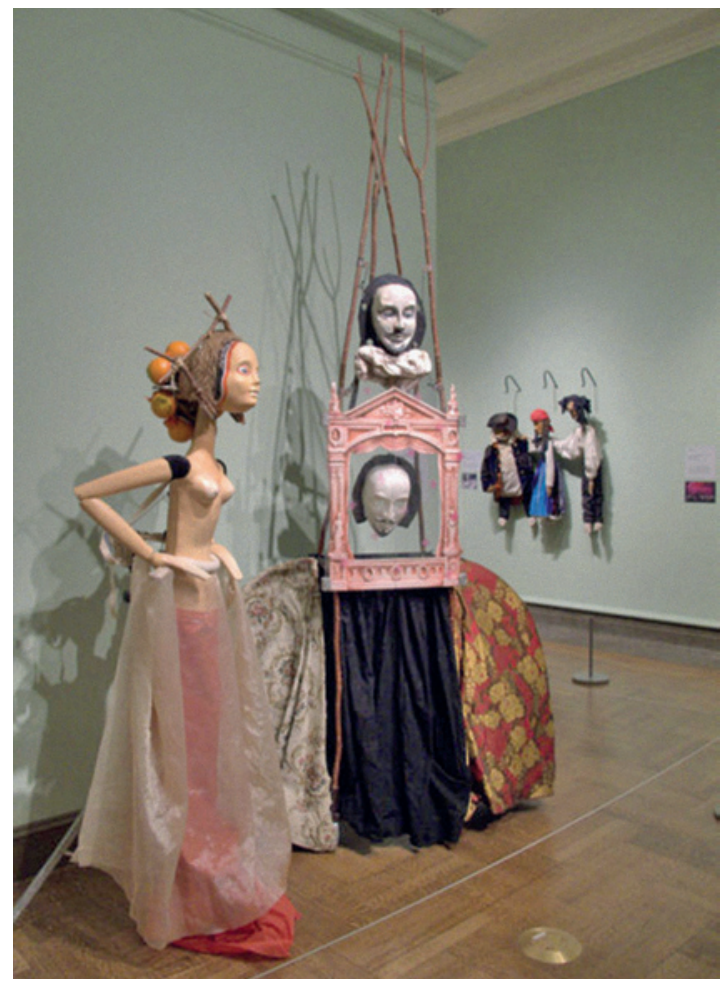

Fig. 1: Installation of figures from Petr Matásek's designs for Miranda and Prospero from The Tempest (2002), collections of the Naïve Theatre, Liberec.

Photo (c) courtesy of the Columbus Museum of Art.

and Irony 2: František Tröster and Contemporary Czech Theatre Design (2004), and Jaroslav Malina: Paintings and Designs (2009). The three previous exhibits were well received by local audiences in general and by critics specifically. This led to a partnership among the Columbus Museum of Art, the Ohio State University, and the Arts and Theatre Institute in the development of a potentially popular Czech puppet exhibit and an accompanying theatre production. The first two words of the title for the exhibition, Strings Attached, was not a simple reference to the marionettes to be shown, but was rather a play on words that referred to the lingering influences - threads of techniques - that can be linked from the past down to the present. Through the exhibition, American audiences were able to connect the lines of puppet development in the Czech lands from nineteenth-century family companies travelling from village to village all the way to twentieth- and twenty-first-century stop action and digital films. 


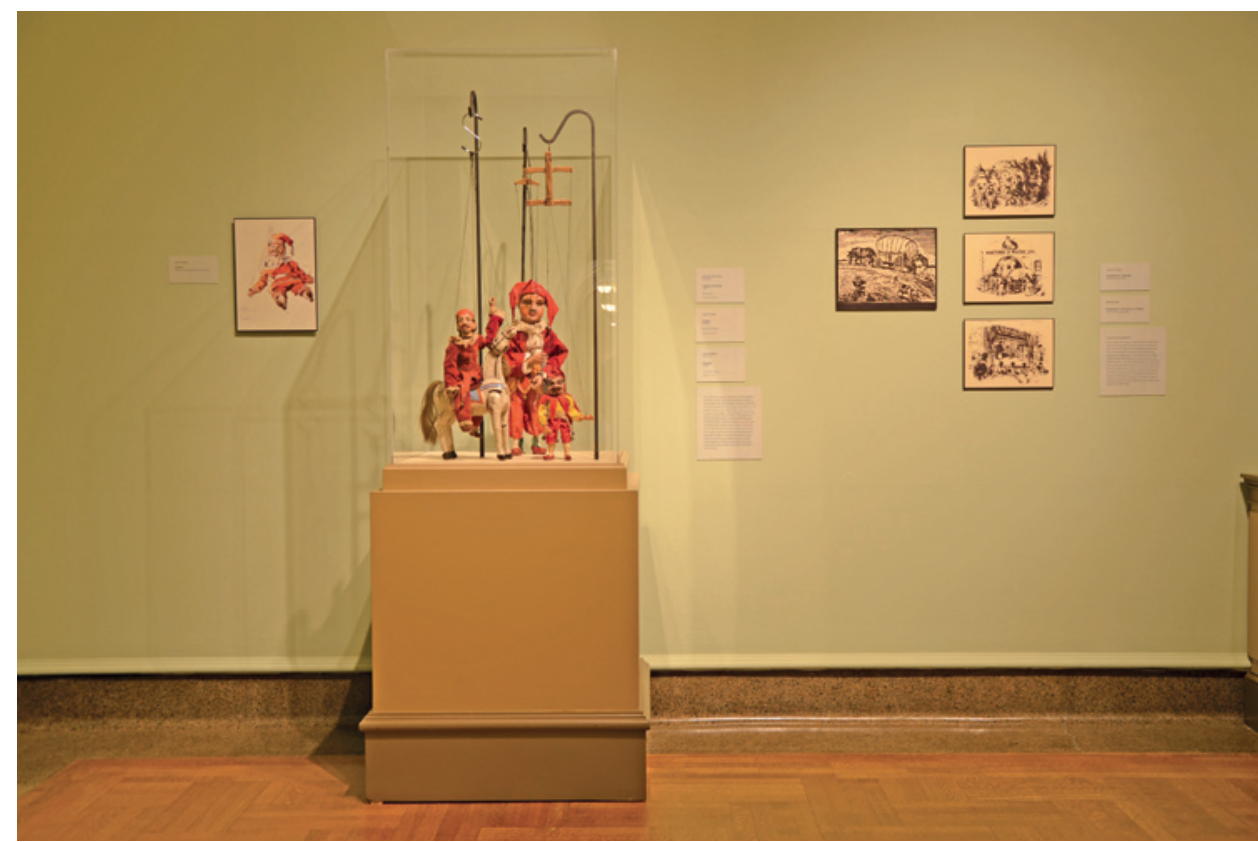

Fig. 2: Two early $20^{\text {th }}$-century versions of Kašparek by Josef Chochol and Josef Adámek, collections of Jiři Vorel, and one $19^{\text {th }}$-century version by Jan Flachs, Jr., collections of Marie and Pavel Jirásek. Photo $\odot$ courtesy of the Columbus Museum of Art.

\section{Strings Attached: The Living Tradition of Czech Puppets}

The exhibition was comprised of over 140 items gathered from a variety of private collections by Nina Malíková and displayed in three rooms. As curator of the Czech puppet collection for the exhibit she amassed a tremendous range of puppets and puppet-related items. In the words of Malíková it was 'the largest exhibition of Czech puppets ever [...] from film puppets to artefacts by artists who were inspired by puppet theatre - it is the first comprehensive presentation of this form of art on this continent' (Strings 2013: 105). The sections of the installation included: 'From travelling String Puppeteers to Puppet Theater Renaissance' ( $19^{\text {th }}$ through early $20^{\text {th }}$ centuries), 'Years of Search, Revolt, and Return to Tradition' (early $20^{\text {th }}$ century to 1989), and 'Paths of Czech Puppet Theater after the Velvet Revolution' (1989 to early $21^{\text {st }}$ century). The installation was supported by numerous explanatory texts and video displays, leading viewers through the development of Czech puppet art while simultaneously placing that development in a historical and geographical context. The catalogue for the exhibit (String 2013) supported the installation with informative essays by Lenka Šaldová ('Traditional Czech Puppets') and Nina Malíková ('Modern Czech Puppets'). An introductory section and an essay targeting local audiences by Beth Kattelman ('The Phenomenon of American Puppetry') coupled 


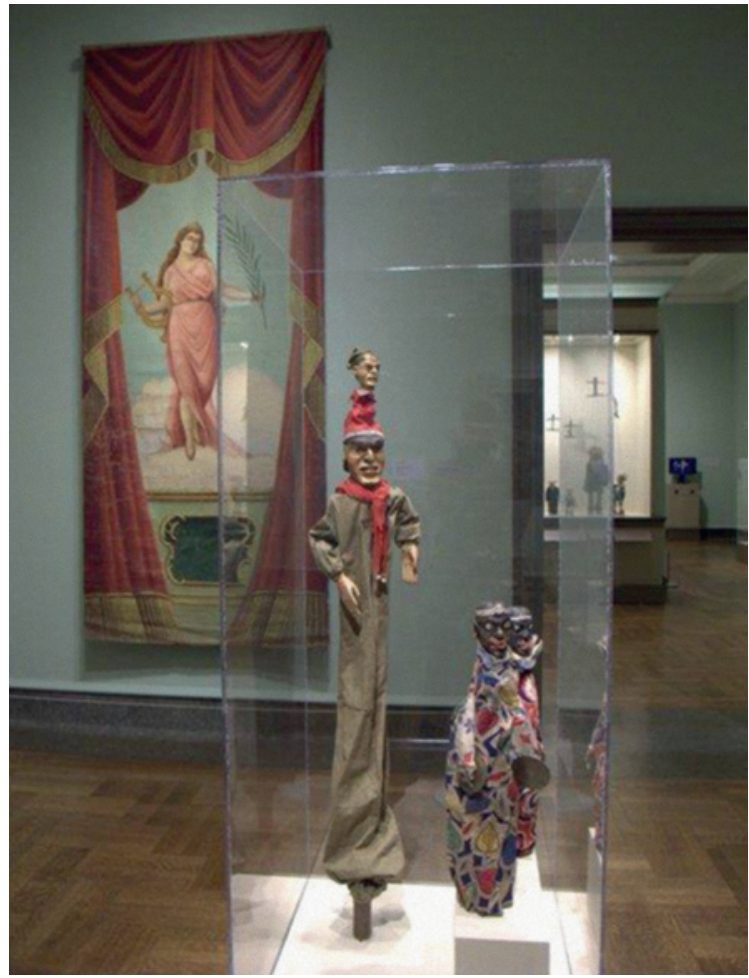

Fig. 3: $19^{\text {th }}$-century trick puppets by Jan Flachs, Jr., collections of Marie and Pavel Jirásek.

Photo (c) courtesy of the Columbus Museum of Art.

with two appendices ('The National Museum, Prague: Its Theater Department and Collection' by Vlasta Koubská and 'Puppet Theaters, Museums, Collections, Organisations, and Publications in the Czech Republic' by Nina Malíková) completed the perspectives provided by the catalogue. It should be noted that the vast majority of the exhibit was comprised of items from private collections. Nina Malíkovás work in acquiring these items was critical to the success of the exhibit. ${ }^{1}$

Among the most popular items for Ohio audiences were the nineteenth-century trick puppets, 'home theatre' display, and the exhibited works by Jan Švankmajer and Petr Matásek. All three of the trick puppets originated in the studios of Jan Flachs, Jr. These non-string puppets were frequently used as entractes for itinerant performers in the nineteenth century. Of the three trick puppets displayed, the Monkey on a Horizontal

1 A full listing of contributors to the exhibition can be found in the catalog (Strings 2013: 103); although the print is sold out, it is available as an eBook (https://bookmate.com/books/YoSgYNs7). Many individual artists provided works and significant private collections such as those belonging to Marie and Pavel Jirásek, Jiř́i Vorel and Alena Vorlová, Via Praga, and Athanor (source of items by Jan Švankmajer) were particularly helpful. 


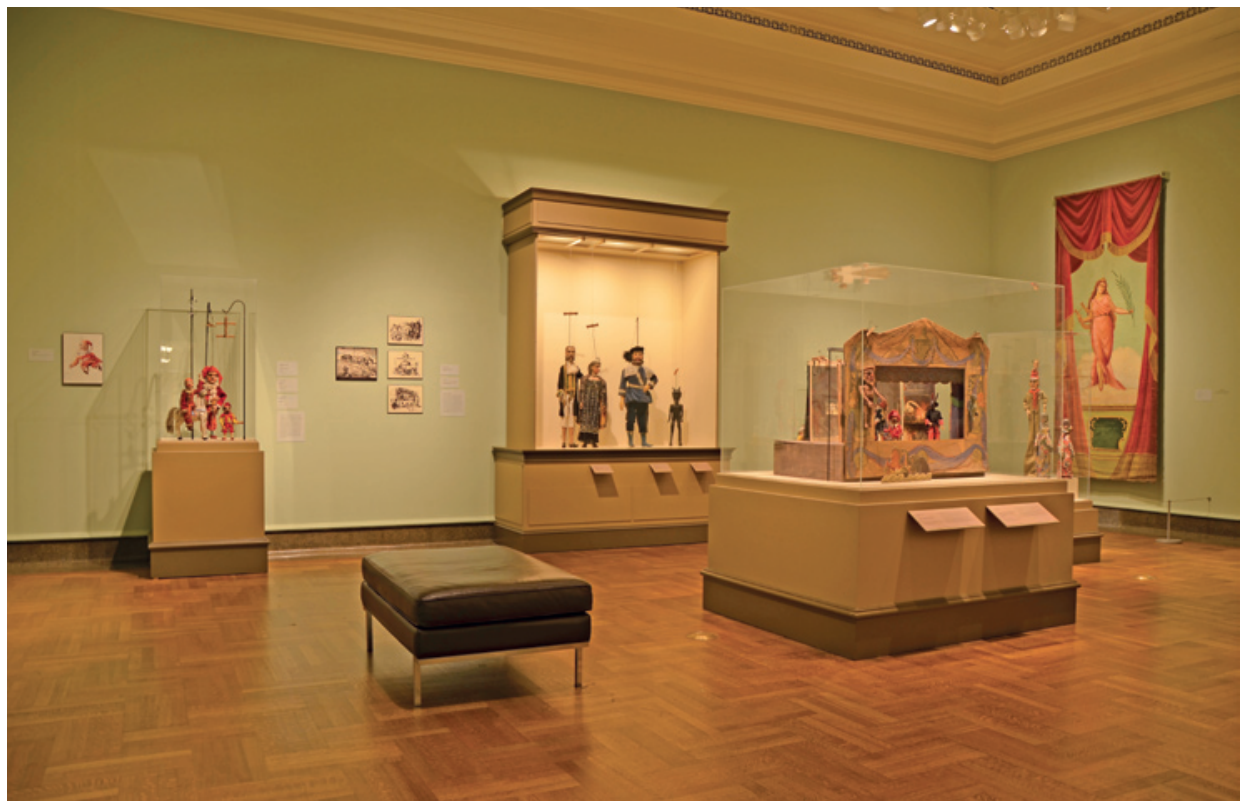

Fig. 4: Alešs Puppet Theatre, 1913, by František Kysela, collections of Marie and Pavel Jirásek. Photo (c) courtesy of the Columbus Museum of Art.

Bar and Blackamoors emphasised a fascination with the exotic that is to be understood in a time when foreign travel was infrequent.

The 'home theatre' phenomenon combined two early twentieth-century factors: the 'revival' of indigenous performance traditions and mass production techniques. During that time many variants of puppets, sets, costumes, and settings were available to individual families and groups. Well-known and respected artists, including Mikoláš Aleš (1852-1913), created items that had the effect of legitimising what before this time had been a popular folk tradition, for urban users. The resulting popularity of these domestic puppet theatres ensured the further development of puppet techniques for subsequent generations.

Another interesting aspect of the exhibit was provided by the work of Josef Skupa. Two versions of Skupa's Spejbl and Hurvínek were shown and drew attention by virtue of an anecdote shared by Nina Malíková. A reporter from the New York newspaper the Wall Street Journal interviewed Malíková during the installation of the exhibition. She told him that both Skupa and the puppets were imprisoned by the Nazis during World War II. The rationale for this imprisonment was the perceived threat posed by not only the voices provided by Skupa, but the objects, Spejbl and Hurvinek, and the combined influence they wielded over Czech audiences at the time. This seeming power of inanimate objects in a politically charged historical moment caught the imagination of all who read the story and built interest in the exhibit as a whole. 


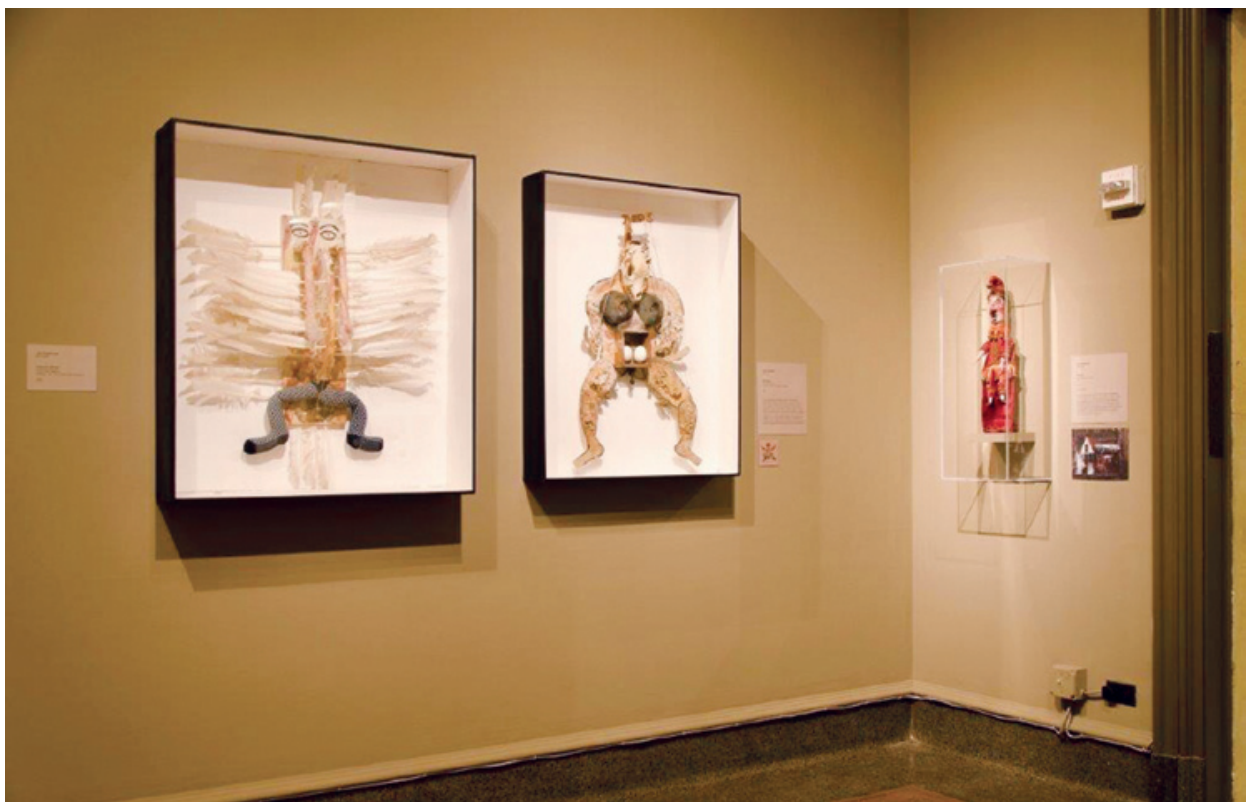

Fig. 5: Androgyn (1990), Icarus' Bride (1990), and Punch (1964) by Jan Švankmajer, collections of Athanor Ltd., film production company. Photo @ courtesy of the Columbus Museum of Art.

The 'string' that appeared to interest many younger exhibition patrons was the connection between puppets, and animated and digital films. American filmmakers such as Tim Burton and the Brothers Quay have previously asserted the influence on their work of Czech artists such as Jiří Trnka, Jiří Bárta and Jan Švankmajer (all of the latter had items in the exhibit), and many of the films by these three Czech artists have direct relationships to puppetry. After viewing the historical panorama of Czech puppetry, American audiences were given the chance to compare what they had seen in the galleries to scenes from recent live action and digital animation films. Many voiced surprise at the number of connections they could see between the artefacts and the films. All three of Jan Švankmajer's items in the exhibit stretched viewer's notions away from traditional puppet usage, but one forged a link with the past. His stringless Punch, from the stop-action film Punch and Judy (1964), bore an unmistakable relationship to the historical representations of Kašpárek marionettes seen in another room of the exhibit.

While the living tradition of Czech puppets undoubtedly endures in performance venues across Europe and around the world, it has truly gained new, young audiences in its adapted form in stop action and digital filmmaking.

The Starr Review, a Columbus area arts blog, described the exhibition as

[t]hree galleries full of high-strung individuals in suspended animation! Each face so individualised; every figure shaped not only by anatomy, but [also] by symbolism and 
its position in a condensed moral narrative. With the exception of some video, the show leaves all the beautiful puppets hanging along the walls or posed in groups under vitrines, sometimes in decorated settings. (STARR 2013)

After describing several specific aspects of the exhibition the writer concludes 'Strings Attached is an art show giddy with an abundance of beautiful material, but it is also a show about stagecraft. [...] It's a rare, multifaceted, and absorbing show. It's a wonder: full of wonders' (STARR 2013).

The opening of the exhibit in March 2013, attended by Pavla Niklová, Director of the Czech Center in New York City, was greeted with an enthusiastic audience. Nina Malíková delivered the keynote address with simultaneous translation provided by Markéta Trösterová Fantová. Over the course of the exhibition in Columbus, Ohio, Strings Attached was seen by 70,681 visitors. The print version of the exhibition catalogue sold out completely. Interest in and conversation about the Czech puppet exhibit persists to this moment among those who saw it. An evidence of the continuing interest in the exhibit is the fact that the puppet/mannequin designed by Petr Matásek for the April 2013 production at Ohio State University remained on display in the lobby of the Columbus Museum of Art over a month after the Czech puppet exhibition closed. Static objects in the form of this exhibit enlivened the minds of exhibit viewers. The question remained: would audiences respond to the use of a puppet-inspired object in free-flowing context of a contemporary live production?

\section{aPOEtheosis - Principle of Horror}

The relatively long timeline required for developing an international exhibit at a fully functioning museum provided an opportunity to develop a stage production that could illustrate contemporary Czech puppet/object techniques and principles. Working with an internationally lauded Czech puppet master whose work would be displayed in the exhibit made perfect sense from both an artistic and educational perspective. It was decided that Petr Matásek and I would develop a new work for our university theatre that would link the frozen past of exhibited items with the kinetic present for live audiences on our campus. Furthermore, the new production would attempt to unite a familiar, American topic with Czech puppetry traditions. Agreeing in principle to the project took very little time. Finding an appropriate subject to explore in the production - that took quite a bit longer. Ultimately, we agreed to use the prose and poetry of Edgar Allan Poe as a basis for our common work.

Petr Matásek is well known for the breadth of his creative activities. Beginning with the world famous puppet company Dragon (Drak) in the 1960s, his work has now been seen in many Prague venues from the crypt at Gorlice (2001) to the Estates Theatre (Stavovské divadlo, National Theatre, 2006) and the Vinohrady Theatre (2013) theatres, 
as well as at the Bouda (PQ 2007) and the MeetFactory (2012). Internationally, Petr has had many experiences with professionals and students in Norway, Australia, Japan, Canada, and the United States. He has been an active participant in the process of 'seeding' groups and individuals with his approach to developing productions from idea to final product. In all cases the idea is fundamental to the process - and not just any idea: it must provide the opportunity to explore multiple possible visual/aural representations and actions in the course of a production. Once E. A. Poe was selected for our exploration, we had to overcome mutual questions concerning the relevance of the subject to contemporary audiences, as well as our concerns about young performers'/audiences' unfamiliarity with the stories and poetry used in the telling of our tale. It was agreed that our approach would: 1) not be a simple restatement of Poe's work; and 2) be intelligible on its own without the requirement of audience expertise with Poe.

For approximately eighteen months before rehearsals began, Petr and I met periodically at Prague cafés for multiple cups of coffee while our Poe discussions germinated. Many sketches were generated by Petr during these sessions and several scenario variants were discussed. Once we agreed upon a scenario which featured several short stories with poetry segments as a connecting device, Petr uttered the critical statement: 'Now we must find the Principle of Horror'. Our version of horror would not involve some facsimile of actual blood or violence but rather transformative actions that occur or are suggested by the works of Poe. Each of these transformations originated in the creative imagination of Poe and thus our punning title arrived: aPOEtheosis - a Fantasy Based on the Life and Work of Edgar Allan Poe.

Our purpose was to develop an association between the historical personage, Poe, and our fictional live version of Poe. The 'horror' of his creative isolation and obsessions might then be clearly seen, and understood, by our audiences. As Petr stated in the unpublished document, 'Principle of Horror':

[The] author dares to draw near dark aspects of man's character, materialises and validates them by use of known, verifiable symbols - a foundering ship, an inquisition dungeon, a black cat, the plague, ill-fated places, or a ruined house. In best [cases, this happens] when a deafening storm and blinding thunderbolts are present at the same [time].

It should be noted that all the symbols expressed above were to find expression in decidedly non-quotidian ways. We sought to establish the horror of our fictive world through the language of dreams. This phase of the development of the production required much consideration and the prodigious application of pen to paper.

Thumbnail sketches and doodles drawn during our conversations took shape when Petr devised the most critical objects needed to complete the horrific visions for our production: a giant raven that appeared and then shifted to the personification of a woman; a simple spindle/top which began as a ship's wheel and then became a mast that spun into the maelstrom of a storm; a light box built into the stage that created deep, shad- 


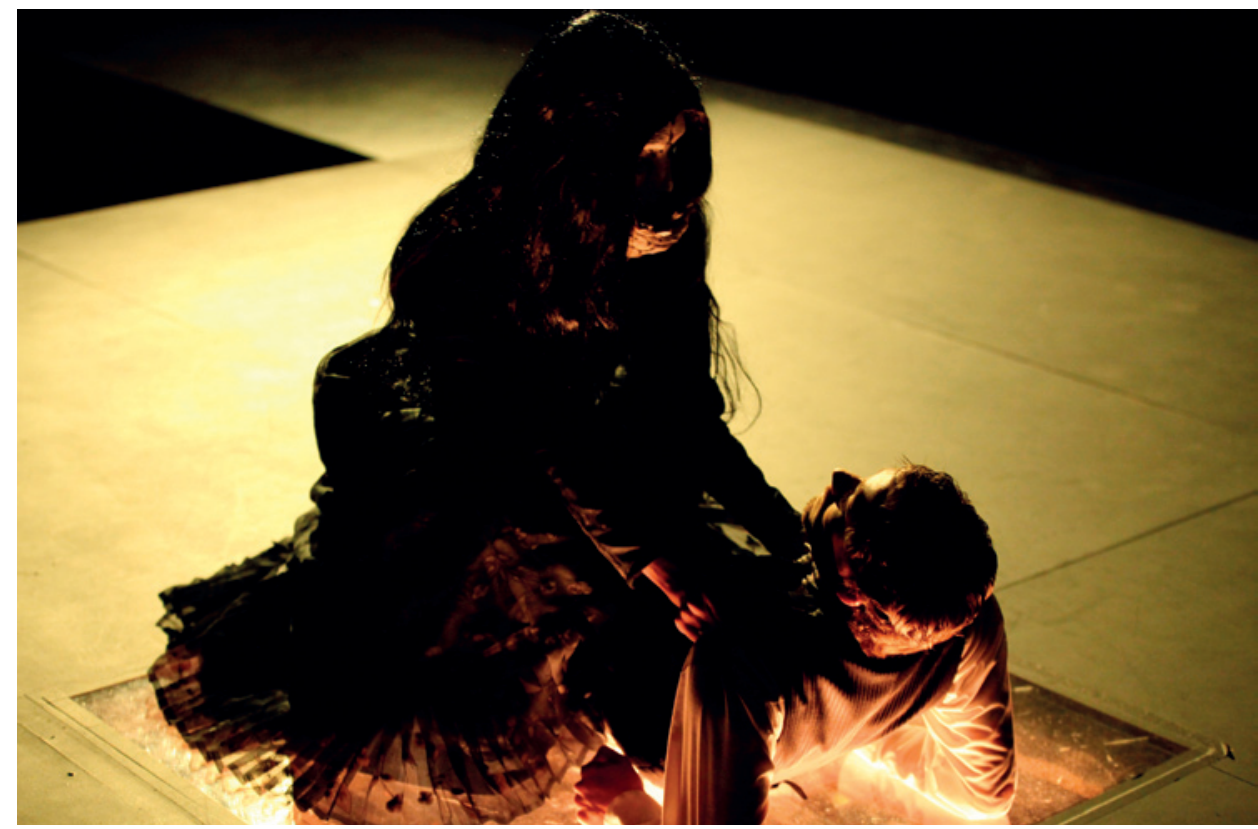

Fig. 6: Production photograph from the Ohio State University production of aPOEtheosis showing Poe tormented by a horrific vision in the 'light box'. Production @ O Ohio State University Theatre.

owy figures of anything illuminated by it; the illusion of a bank of seats that mirrored those in the auditorium and which split open to reveal a door to hell/eternity/another world; and, most importantly, a puppet-inflected mannequin of a woman which could be manipulated by actors and deconstructed/reconstructed as needed in the production. The latter object was designed by Petr Matásek and then built by master craftsman Jiří Bareš in his workshop near Hradec Králové. ${ }^{2}$ It was shipped to the United States for the production and was then acquired by the Czech Collection at the Theatre Research Institute at Ohio State University after the performances ended. Matásek gave this object the punning name Marion Lee, an acknowledgement of a famous character from Poe (Annabelle Lee) and the stringless 'marionette' influences that it displayed.

\section{Marion Lee - Femme Fatale}

Marion Lee was a key 'actor' in the production, standing in for Poe's fascination with and attraction to beautiful, intelligent, and ultimately unattainable women. The prose sections of the text were drawn from 'The Masque of the Red Death', 'The Tell Tale Heart', 'The Pit

2 Jiř́ Bareš is a master woodworker who followed the traditional path of puppet makers in the Czech homelands. In addition to his work on puppets he also repairs/recreates religious sculptures. This tradition was abundantly displayed in many of the objects in the Strings Attached exhibit. 

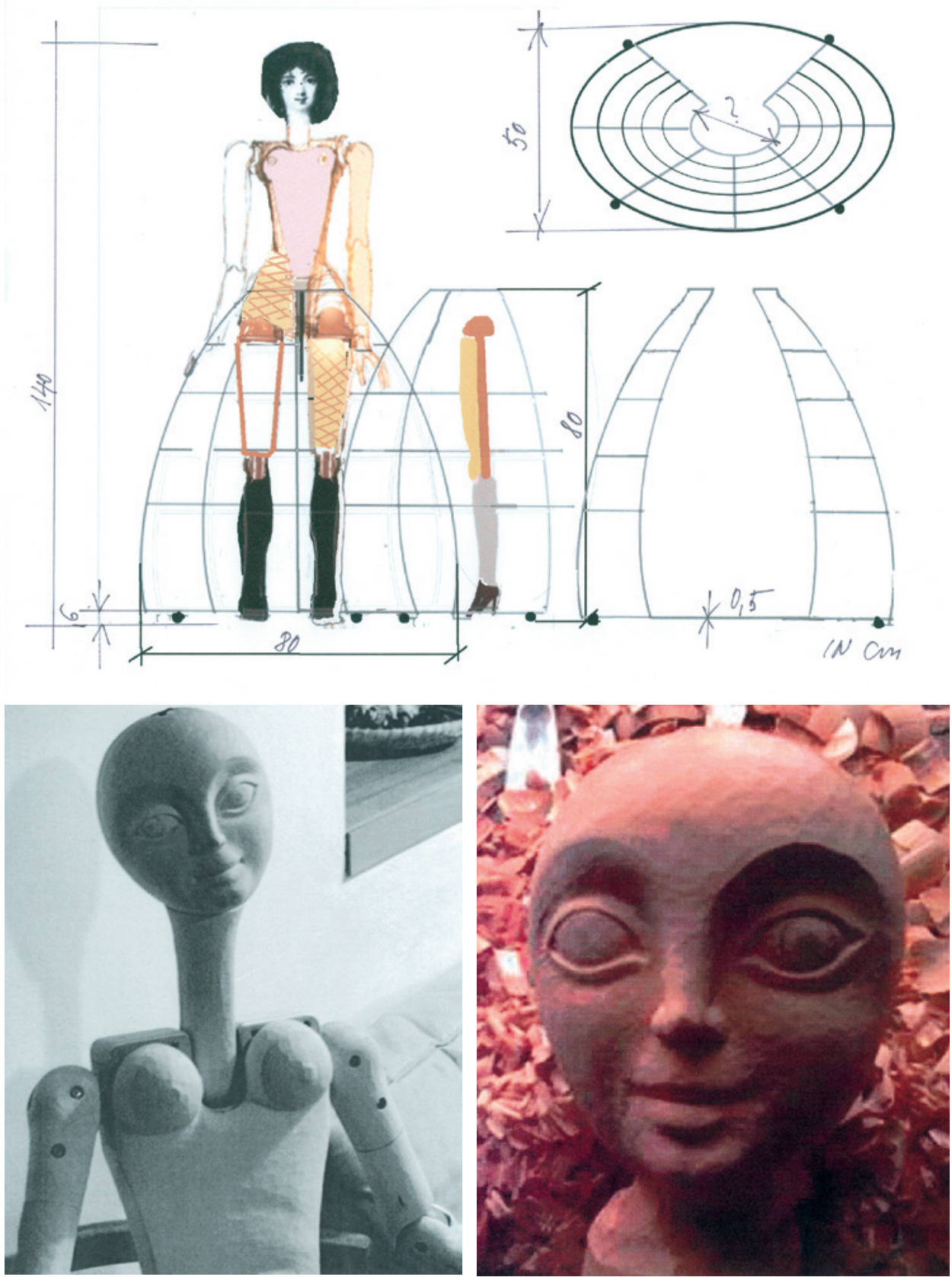

Fig. 7a-c: Photograph of the Marion Lee puppet,

showing design with dress frame (a), torso carving (b) and head on a bed of wood shavings (c). Photograph (C) Joseph Brandesky. 


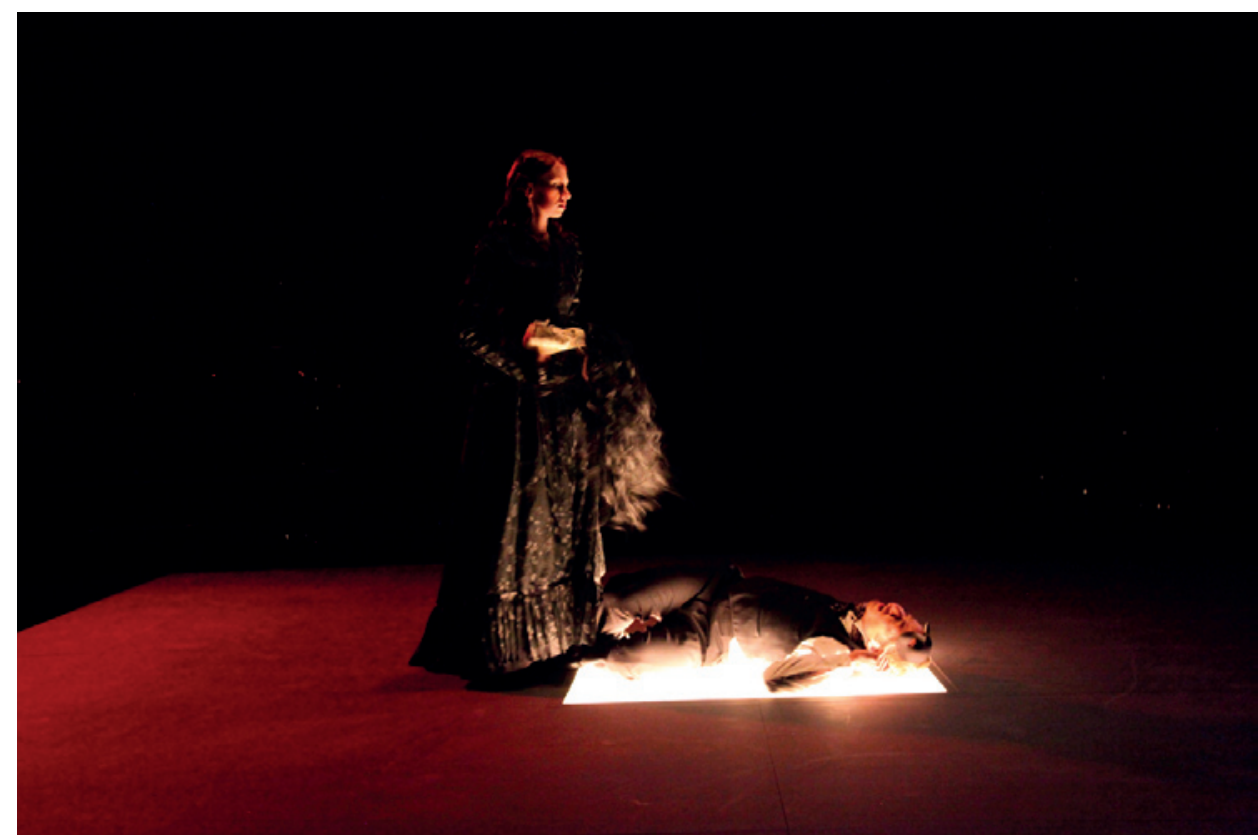

Fig. 8: Photograph from the Ohio State University production of aPOEtheosis showing Poe with with a human femme fatale. Photograph (C) Ohio State University Theatre.

and the Pendulum,' The Oblong Box', and 'The Fall of the House of Usher'. Excerpts from numerous poems ('To Helen,' 'The Bells', 'The Raven', 'Annabel Lee', among many others) concerning Poe's relationships with women - both positive and negative - comprised interludes between the tales. Marion Lee was built to be constructed/deconstructed by actors during the course of the production. She was also exclusively manipulated by the women in the cast. They spoke for her, made her dance, and animated her as atem of Poe's obsession with a perfect, sublime, but physically unreachable woman. Through the interactions of object and actors, Marion Lee attained the ghostly presence found in many of Poe's works.

There were several other visual aspects of the design that survived the planning process but were discarded during rehearsals. A late developing aspect of the design was video projections, which were finally executed by one of Petr's students from DAMU (Antonín Šilar) who came to Ohio State University to help realise the production. Šilar's careful depiction of a live beating heart, projected on the thrust stage during 'The Telltale Heart' section of the production worked very well; but the most effective projection was the use of a swinging bar of light, accompanied by a whooshing sound effect, to approximate the mass and scale of the blade in 'The Pit and the Pendulum' movement. The 'horror' in this scene was palpable, even though there was no real blade or blood used in the scene. Audience reaction afterward attested to the effectiveness of this moment of abstract horror. 


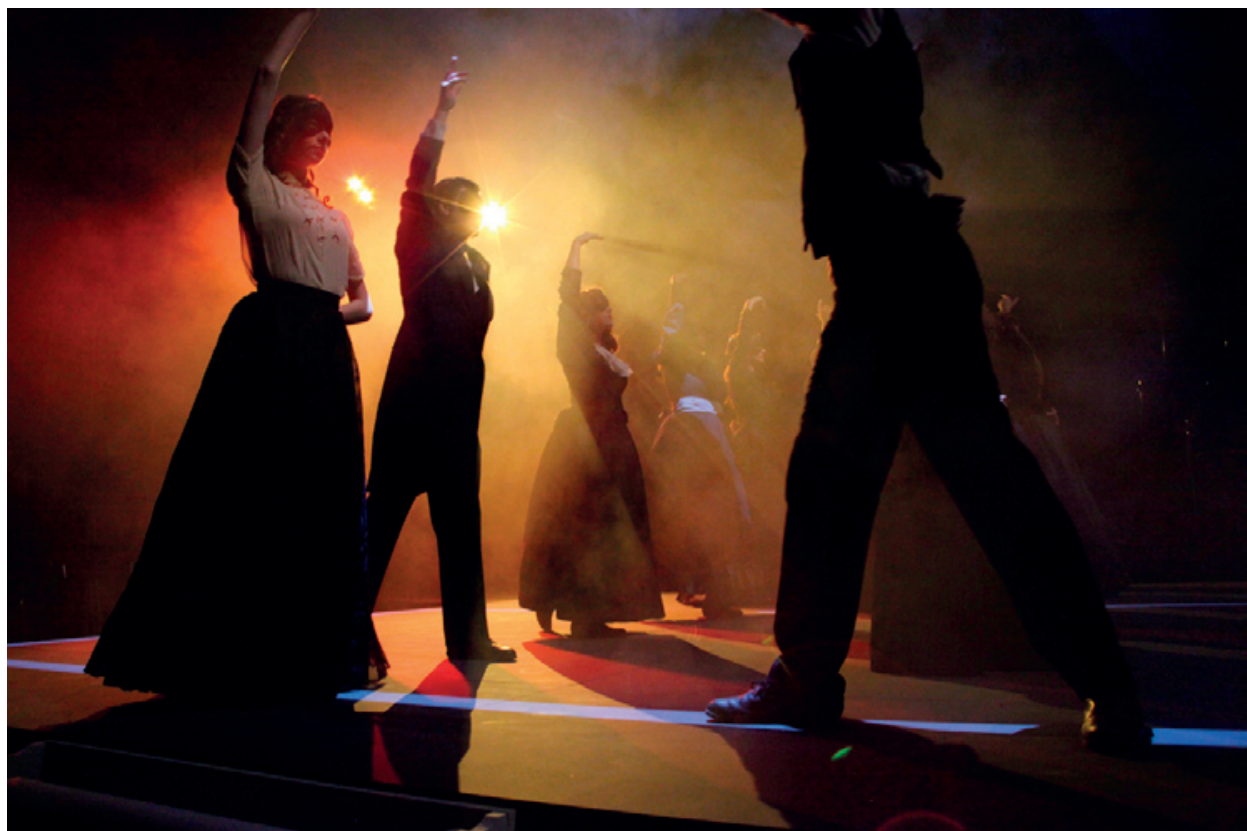

Fig. 9: Photograph from the Ohio State University production of aPOEtheosis showing Poe with and actors dancing during the Masque of the Red Death sequence. Photograph (c) Ohio State University Theatre.
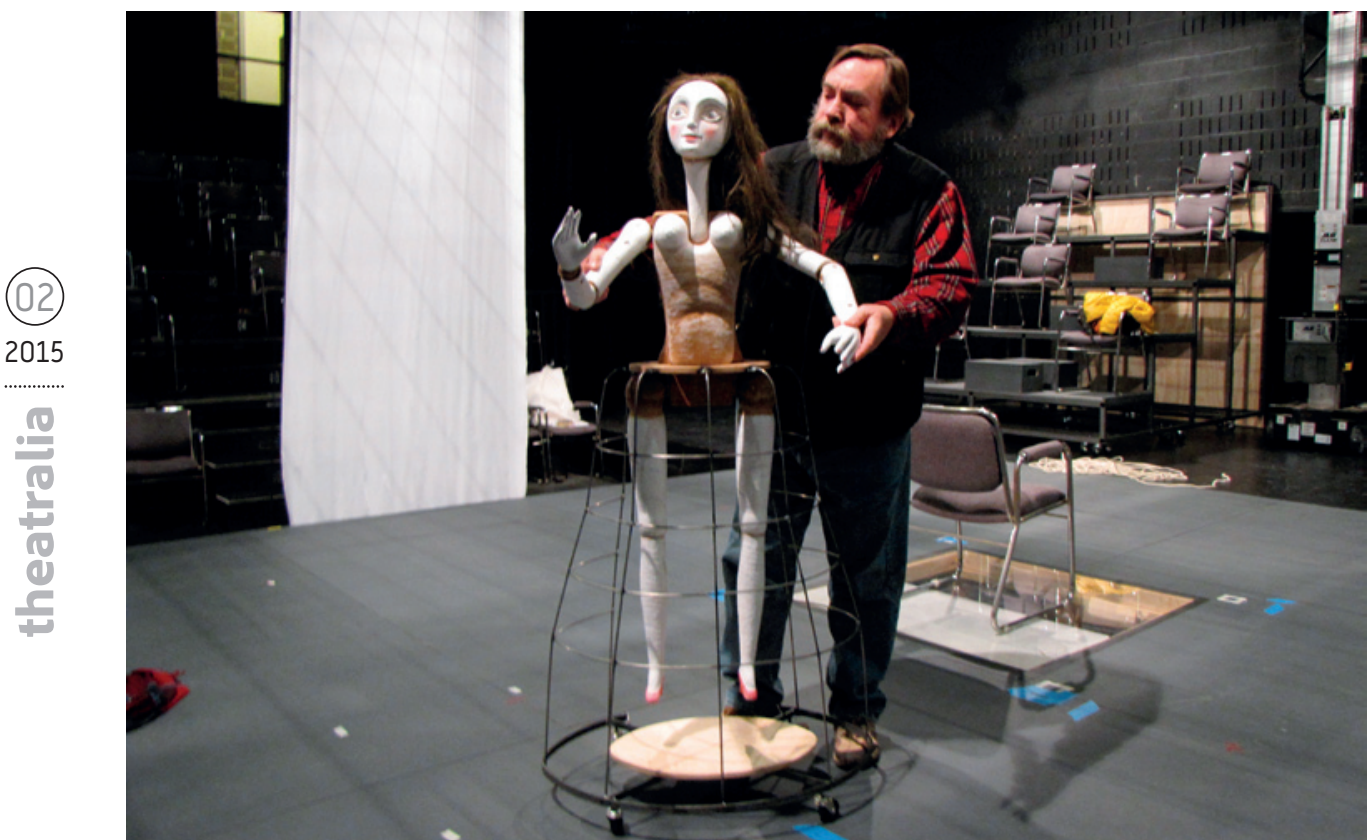

Fig. 10: Joseph Brandesky and Marion Lee. Photograph (c) Ohio State University Theatre. 
As stimulating as the application of video technology was for the production, it was the haunting interaction between an inanimate puppet/mannequin and human actors that produced many of the most foreboding moments. Marion Lee was a spectral presence that engendered visceral responses in audience members. During the final scene, 'The Fall of the House of Poe', female actors entered the space and taunted Poe with the deconstructed arms and legs of Marion Lee. His phantoms attacked him with 'parts' of his obsession. At a conference held during the performance run, a question was asked whether the 'deconstruction' of Marion Lee was in fact a dangerous reflection of the violence done to women throughout history. Although other women at the conference did not see that perspective in the production, the question was nonetheless a testament to the power that the inanimate has in human imaginations. The story of the incarceration of Josef Skupa's 'harmless puppets', Spejbl and Hurvínek, and their perceived power, was palpably echoed in the presence of Marion Lee in aPOEtheosis.

\section{Czech Puppets in Stasis and Flux}

The fortunate confluence of a large exhibition of Czech puppets and a live production fundamentally conceived with Czech puppet techniques provided Ohio audiences with a singular opportunity in 2013. Historical applications of Czech puppet techniques and their more contemporary usages in stop action and digital film were clearly in evidence at the exhibit of Strings Attached while postmodern combinations of puppets/actors/ video/sound/dance/text were explored in aPOEtheosis. The opportunity to explore the possibilities of these two events and their relevance in our time proved unique and illuminating for Ohio audiences both in the gallery, and in the theatre.

\section{Bibliography}

Strings Attached - The Living Tradition of Czech Puppets. 2013. Exhibition Catalogue. Columbus Museum of Art: Columbus, $\mathrm{OH}, 2013$. Available as an eBook at $<$ https://bookmate.com/ books/YoSgYNs7>..

STARR, Ann. 2013. Czech Puppets and Their Tradition at the Columbus Museum of Art. The Starr Review. 6 May 2013. Accessed August 2014 < http://starr-review.blogspot.co.uk/2013/05/ czech-puppets-and-their-tradition-at.html >. 
Joseph Brandesky

Stasis and Flux: Czech Puppet Culture in Columbus, Ohio (Winter/Spring 2013)

\section{Summary}

This article documents the exhibition of traditional and modern Czech puppets entitled Strings Attached: The Living Tradition of Czech Puppets (2013) hosted at the Columbus Museum of Art in Columbus, Ohio, curated by Joseph Brandesky and Nina Malíková. The exhibition was accompanied by a university theatre production aPOEtheosis realised by Brandesky and the leading Czech puppet scenographer Petr Matásek.

\section{Keywords}

Czech puppet theatre, exhibitions, Columbia Museum of Art, Petr Matásek

DOI: $10.5817 /$ TY2015-2-12

Joseph E. Brandesky (brandesky.1@osu.edu) is a specialist in Russian and Czech theatre, based at Ohio State University (USA). He has developed several theatre design exhibits, amongst others: Jaroslav Malina: Paintings and Designs; Metaphor and Irony 2: František Tröster and Contemporary Czech Theatre Design; and Metaphor and Irony: Czech Scenic and Costume Design 1920-1999. His book Czech Theatre Design in the Twentieth Century: Metaphor and Irony Revisited (2007) was published by the University of Iowa Press as part of its Studies in Theatre History and Culture series. In 2013, he curated with Nina Malíková a Czech Puppet exhibit at the Columbus Museum of Art (Ohio, USA) entitled Strings Attached: The Living Tradition of Czech Puppets. 